\title{
SAÚDE MENTAL E INTERNAÇÕES COMPULSÓRIAS NA PERSPECTIVA DA BIOÉTICA E DOS DIREITOS HUMANOS E FUNDAMENTAIS: UMA INVESTIGAÇÃO CRÍTICA DO CASO DA “CRACOLÂNDIA” NA CIDADE DE SÃO PAULO
}

MENTAL HEALTH AND COMPULSORY INTERNATIONS IN THE PERSPECTIVE OF BIOETHICS AND HUMAN AND FUNDAMENTAL RIGHTS: A CRITICAL ANALYSIS OF THE “CRACKLAND” CASE IN THE CITY OF SÃO PAULO

Ingo Wolfgang Sarlet

Gabrielle Bezerra Sales Sarlet

\section{RESUMO}

Trata-se de investigação bibliográfica e qualitativa, jurídica e bioética, sobre a evolução do tratamento aplicado às pessoas acometidas por transtornos psíquicos, notadamente os dependentes químicos, visando a compreender as práticas de internação compulsória e oferecer alternativas ao estigma e à exclusão. Fundamenta-se no princípio da dignidade da pessoa humana. Consiste em análise crítica da proteção assegurada aos deficientes psíquicos no Brasil e das políticas públicas de enfrentamento da drogadição, para refletir sobre a polêmica intervenção na "cracolândia" da cidade de São Paulo e os seus desdobramentos, mediante análise jurídico-constitucional da legitimidade de tais intervenções e das internações compulsórias.

Palavras-chaves: Saúde mental. Bioética. "Cracolândia".

\section{ABSTRACT}

The article seeks, through a bilbiographic and qualitative investigation, based on legal and bioethical parameters on the evolution of the treatment applied to people affected by psychic disorders, especially the chemical dependents, to understand the panorama about the practices of compulsory hospitaliza- 
tion and offer hypotheses to stigma exclusion, mainly based on the application of the principle of the dignity of the human person. This is a critical analysis of the protection afforded to the mentally handicapped in Brazil in the face of the wave of drug addiction and public policies to confront this problem and to reflect on the recent intervention undertaken in the "cracolândia" of São Paulo trough a constitutional and legal analysis of the legitimacy of those interventions and compulsory internations.

Key Words: Menthal Health and Drugs Addiction. Bioethics. Crackland.

\section{INTRODUÇÃO}

A loucura é um conceito relacional e extremamente democrático. Distinta, porém, é a sua abordagem e a aplicação da terapêutica à casuística. Com efeito, ora a Loucura é considerada como uma ligação com o divino (AMORTH, 2010), com o sobrenatural, sendo a pessoa que a manifesta reconhecida como um ente superior, uma espécie de oráculo para o grupo social no qual se insere, ora a loucura é tratada como algo nocivo, danoso, infrutífero, deficiente. Logo, perene é a atualidade da indagação acerca da natureza da loucura, ou seja, acerca da fronteira entre o normal e o anormal (BASTIDE, 1967), sobre os seus desdobramentos sociais, políticos e jurídicos, e sobre as formas mais adequadas de sua abordagem.

Destarte, o que prioritariamente exurge em relação a esse conceito é a extrema carga emocional com a qual ele é usualmente abordado. Isso se deve à natureza subversiva ínsita ao conceito de loucura. A despeito da sua ambiguidade, será utilizada a tradicional expressão saúde mental apesar de ser mais adequado o termo saúde psicológica em razão da sua abrangência e atualidade e, no que toca à legislação atual, a expressão deficiência psíquica. À guisa de ilustração, salienta-se que, de modo geral, no Ocidente, os doentes mentais tem sido tratados da mesma forma que os leprosos no medievo e, portanto, excluídos do seio coletivo.

Sempre esteve aliada à contestação, à denúncia e à exaltação e, com isso, se tornou um dos maiores estigmas do Ocidente (RODRIGUES, 1999). Ela ainda é, nos dias atuais, mesmo que inconscientemente, entendida como algo mistificado, um mal do espírito, sinônimo de desgraça e alvo de repulsa. No século XIX, e.g., como um legado do higienismo (STEPAN, 
2005), passou a ser entendida sob o enfoque do binômio (MENDES, 2013) saúde-doença (GONÇALVES, 2009) que ainda vem pautando a discussão sobre o tema e justificando, a princípio, algumas intervenções radicais e restrições no âmbito de aplicação dos direitos humanos e fundamentais (SARLET; FIGUEIREDO, 2011). Da dicção de Monteiro (2016), destaca-se a inexistência de um conceito de doença mental universalmente aceito. Segundo ele, em razão da sua complexidade, o mais importante é analisar se a pessoa apresenta algum padrão de comportamento patológico prejudicial à vida cotidiana e, desse modo, buscar a melhor alternativa de tratamento cientificamente válido, uma vez que se trata de estado de afetação multifatorial.

0 episódio envolvendo o recente processo de internação compulsória coletiva e de evacuação da assim chamada "Cracolândia", na região central da cidade de São Paulo, recolocou o assunto - embora de modo polêmico e mesmo trágico - na agenda da mídia, com repercussão na Sociedade e mesmo na esfera política e judiciária. Além disso, os fatos veiculados nos órgãos de comunicação social e também nas mídias sociais, embora evidentemente não possam ter retratado a integralidade dos fatos e muito menos ter transmitido com completude e total fidedignidade toda a dramaticidade do ocorrido, tiveram suficiente impacto para atrair a atenção da população, gerando tanto aplausos quanto indignação e crítica.

0 presente estudo intenta analisar alguns aspectos da história da saúde mental em algumas das principais fases da história da Humanidade e do Brasil para, mediante reflexão sobre o panorama atual acerca das práticas de internação compulsória, orientada pelo marco normativo dos direitos humanos e fundamentais, mormente das pessoas com deficiência, e pelo prisma bioético, oferecer hipóteses alternativas ao estigma, à ditadura da normalidade e à exclusão frequentemente identificadas na maioria das políticas públicas nacionais, de modo a assegurar a dignidade humana das pessos com deficiência psíquica e em especial, levando em conta o foco do presente texto, das pessoas com dependência química.

A pesquisa se posiciona a partir de um referencial crítico para refletir, em geral, sobre a realidade dos pacientes com acometimentos psíquicos no Brasil face à atual constelação de direitos das pessoas com deficiência, para, na sequência, problematizar e refletir sobre os diversos aspectos 
atinentes ao polêmico episódio envolvendo a intervenção (representada por diversas medidas invasivas de direitos humanos e fundamentais) empreendida na chamada cracolândia da cidade de São Paulo e sobre os seus desdobramentos para a afirmação dos direitos e das garantias da parcela da população brasileira atingida, procedendo a uma análise do instituto das internações compulsórias na legislação brasileira no sentido de avaliar a sua legitimidade jurídico-constitucional e sua sintonia com o marco normativo dos direitos humanos e fundamentais das pessoas com doença mental e/ou dependência química. Com isso também se pretende discutir os problemas que envolvem a ausência, a precariedade e mesmo os equívocos da maioria das políticas públicas que tem por objeto o enfrentamento do problema da drogadição no país.

\section{SAÚDE MENTAL: UMA BREVE CONTEXTUALIZAÇÃO HIS- TÓRICA EM TERMOS GERAIS E SOBRE A EVOLUÇÃO DA QUESTÃO NO BRASIL}

O modelo de internação, forjado na Idade Média, pouco se alterou (ARBEX, 2013), caracterizando-se pela hierarquização e pelo abismo identitário (TIEDEMANN, 2016) no tratamento do doente, de modo a mantê-lo distante da Sociedade e dele mesmo. Enclausura-se o débil, menos para seu benefício e tratamento, que para uma espécie de higienização social. Na esfera pública, o pressuposto para a cidadania é a co-existência entre iguais. Retirar abruptamente o sujeito dessa esfera constitui uma forma extrema de ceifar sua liberdade e restringir a sua humanidade (SUPIOT, 2012).

A doença mental se caracteriza pela atemporalidade. Em todas as sociedades e em todos os tempos, ela se fez presente, lembrando a fragilidade da mente humana e a existência de um universo desconhecido dentro de nós mesmos. Nem todas as culturas a trataram como algo negativo, desviante ou doentio. Cada Sociedade a considerou diferentemente, umas reprimindo, outras exaltando (PEREIRA,1985). A realidade é que se trata de uma decisão social e política, em que a Sociedade escolhe e delimita as características afeitas à coletividade, erigindo o padrão de 
normalidade. Tudo fora desse esquadro se considera louco, anormal, desviante (PEREIRA,1985). Pressupondo essa relação dualística e excludente, na medida em que se considera algo como normal, preferível, benéfico e positivo, considera-se, consequentemente, seu revés como patológico, mal, impróprio e perigoso, isto é, algo a ser expurgado do mundo social. Consiste em realidades interdependentes, em que, do ponto de vista da lógica binária, uma delineia os contornos da outra.

Durante um largo período no Medievo, mais especificamente a partir dos séculos VI e VII, a lepra foi um mal epidêmico em toda a Europa. Esse mal se difundiu devido ao contato do homem europeu com o Oriente, por meio das Guerras Santas, que legavam tal acometimento aos cavaleiros cruzados, e, por conseguinte, a toda a Europa. Criou-se, então, uma cultura de medo ao redor da figura da lepra e do homem leproso. "As deformidades físicas causadas pela lepra chocavam o homem medieval, para quem o corpo nada mais era do que um reflexo do espírito" (PINTO,1995). Para extirpar a doença, surgiu o costume segregatício de encarceramento e de exclusão social, trancafiando o leproso longe de qualquer convívio humano (PINTO, 1995).

Durante a Idade Média, mais especificamente no século XIV, a lepra 'desapareceu' do mundo ocidental, caindo bruscamente o número de leprosos internados. Essa redução se deu não devido às práticas médicas destinadas a sanar tal mal, mas sim pela segregação e pelo rompimento com os focos orientais da infecção, com o fim das Cruzadas, restando os leprosários quase que desativados. Após a derrocada da lepra, o homem necessitou pôr em seu lugar um novo mal a ser expurgado pela sociedade (FOUCAULT, 2012). Mesmo com a diminuição dos casos de lepra, permaneceu inalterada a estrutura arraigada da exclusão, da intolerância e do internamento de todos os diferentes ou os que afetassem a ideia de normalidade. Os lugares outrora sacros da lepra passaram a abrigar "pobres, vagabundos, presidiários e 'cabeças alienadas'” (FOUCAULT, 2012). E assim, gradativamente, a loucura foi tomando o espaço que antes era destinado à lepra.

Porém, antes da loucura ocupar o espaço deixado pela lepra, ela já estava presente nas experiências da Renascença. Esta viu surgir uma nova e estranha figura ao longo dos canais flamengos e dos rios da Renânia: a 
Nau dos Insensatos (FOUCAULT, 2012). Tal medida implicava no banimento dos seres indesejados em razão da sua incontestável rebeldia e de sua insubordinação aos padrões sociais. Com isso, o doente mental era transferido para um além- mundo. De fato, ele era, em regra, paralisado na sua arte de subverter a ordem estabelecida, de forma que lhe era retirada a simples possibilidade de ser ouvido, de ser visto, de ser reconhecido em sua humanidade. Torna-se perceptível que não havia uma política de tratamento. A única medida era a higienização da cidade, isto é, era eliminá-los da esfera pública, escondendo-os da população (FOUCAULT, 2012).

Mais adiante, acima de tudo, na literatura e no teatro renascentistas, o acometimento mental ganhou lugar de destaque na busca da essência da razão e da verdade. Passou-se então a se exaltar a loucura em detrimento de outros temas, como a morte. A loucura passou a ser, então, melhor aceita e menos temida, tornando-se como algo inerente ao homem, intrínseco à própria razão (FOUCAULT, 2012). É nesse movimento dialético que a loucura e a razão encontraram seu equilíbrio, uma somente existindo em razão da outra. Loucura e razão como duas faces (ROTERDAM, 1995) de uma mesma moeda (FOUCAULT, 2012).

0 período Renascentista, que acolheu muito bem a loucura em seu seio, tornando-a algo aceitável e, diríamos até, familiar, foi superado por um Classicismo frio e impiedoso (FOUCAULT, 2012). A Era Clássica desconstruiu todo o prestígio que a loucura conseguiu erguer em torno de si própria durante os séculos posteriores. "A loucura, cujas vozes a Renascença acaba de libertar, cuja violência, porém ela já dominou, vai ser reduzida ao silêncio pela era clássica através de um estranho golpe de força." (FOUCAULT, 2012) Ela passou a ser tratada com o encarceramento massivo sem nenhuma preocupação com a cientificidade e, assim, foi calada, menos de forma natural que por meio da reclusão. (FOUCAULT, 2012). Os doentes mentais, em regra, desde então, passaram a ser tratados como animais, de forma coercitiva, em estabelecimentos que muito se assemelhavam às jaulas de zoológicos. A animalidade passou a ser a forma mais fácil para "curá-los". A loucura, para ser sanada, sob esse ponto de vista, precisaria apenas ser domesticada (FOUCAULT, 2012).

É notável que o processo de alienação do acometido por transtornos psíquicos implicou paulatinamente na restrição e na perda completa de 
seus direitos, na perda do seu reconhecimento como membro da espécie humana, uma vez que, segundo os doutrinadores da época, faltava a eles a característica humana essencial: a racionalidade. Isso implicou inclusive na alteração da terminologia que outrora se utilizava, sendo comum os termos alienação, loucura e seus derivados. Aplicava-se a lógica binária em que a loucura era associada à desrazão e, assim, à perda da condição humana, restando o status decorrente de humano decaído. A lógica binária, portanto, era o padrão utilizado para opor a razão à desrazão tal qual se fazia em relação ao bem e ao mal, as trevas à luz, ao sagrado em relação ao profano e, notoriamente, a saúde à doença.

A modernidade, por sua vez, também reforçou a supremacia da ideia de normalidade ao apontar para a entronização da razão no lugar outrora ocupado por Deus. E, dessa forma, recrudesceu a exclusão na medida em que estabeleceu como principal forma de abordagem da doença mental o modelo hospitalocêntrico. Medidas resultantes desse modelo, visando a higienização das populações se tornaram frequentes e deram ensejo às práticas eugênicas que perduraram até o início do século XX. Mediante essas práticas, as pessoas afetadas na sua saúde mental não eram apenas banidas, mas destituídas de todo e qualquer direito, passando a serem vistas como uma subcategoria da Humanidade. A partir desse legado da modernidade no que toca à saúde mental, se torna evidente que, dentre as diversas modalidades de deficiência (ARAÚJO, 2008), a psíquica é a que tem sido mais negligenciada em termos de empreendimentos que propiciem à inclusão.

Até meados do século XX, poucas mudanças foram registradas em relação às estruturas de internação e no trato do sujeito psiquicamente vulnerado, ainda vigorando o modelo de internação, de repressão e de exclusão social. Dentre outras, havia a exclusão social, pela retirada do sujeito do convívio da sociedade; a exclusão jurídica, em razão da impossibilidade de realização de atos no mundo civil (interdição); e a exclusão familiar, pela perda da condição humana (ARENDT, 2003).

Disseminar a cultura do medo e a falsa ideia de periculosidade (RODRIGUES, 1999) do doente mental foi uma tática extremamente funcional no passar dos séculos, o que criou, no imaginário coletivo, a noção de que o 'louco' não deveria gozar a plena liberdade de locomoção e de convi- 
vência com os 'normais', pois poderia lhes causar mal por sua natureza débil (SARRETA, 2005). Outro aspecto é o fato de que o diagnóstico da insanidade mental, além das implicações sanitárias, acarretava sérias e perversas implicações políticas (FOUCAULT, 2012). Portanto, a depender do caso, o diagnóstico passou a ser um vaticínio (ROUDINESCO, 2008) ou uma bençäo irremovível (FOUCAULT, 2012), jamais um direito humano e fundamental devidamente assegurado.

No que tange à evolução da questão no Brasil, é preciso sublinhar que a tradição hospitalocêntrica para o tratamento da doença mental consiste em um legado da colonização portuguesa. Os hospícios e manicômios brasileiros, então, se tornaram pouco a pouco celeiros de seres humanos amontoados, submetidos às degradantes condições, ou seja, isentos de qualquer vestígio de proteção do Estado. A sociedade civil, expressando seus preconceitos, já havia sentenciado, desde o Brasil colônia, o abandono aos portadores de transtornos psíquicos e, de fato, o Estado apenas tratou de empreender isso, institucionalizando-o. Assim, o Brasil pode ser reconhecido como um dos locais em que houve maior desrespeito à dignidade dos pacientes com deficiência psíquica na medida em que houve o aprimoramento da noção excludente advinda do legado eurocentrista e o aprimoramento e a solidificação em solo nacional de práticas de extrema crueldade em relação a essas pessoas (ARBEX, 2013).

Com efeito, no apogeu do movimento alienista, particularmente no Brasil, grassou em todo o território nacional a prática da internação dos doentes mentais em casas psiquiátricas e em manicômios. No histórico brasileiro, o ápice do horror do regime de internação se deu no Hospital Colônia, em Barbacena, Estado de Minas Gerais, fundado em 1903. Estima-se que, entre 1960 e 1970, 60 mil pessoas perderam a vida no Colônia (ARBEX, 2013). Pacientes submetidos a torturas, sem prontuários, sem registro civil, com total falta de higiene e de alimentação geraram mortes em massa, encetando a produção de cadáveres abandonados ou vendidos para as direções dos cursos de medicina das redondezas (ARBEX, 2013).

Os anos 70, todavia, trouxeram mudanças, dentre elas a visita de Michel Foucault ao Brasil que influenciou uma geração de estudantes de medicina e de médicos que passaram a protestar por melhores condições de trabalho nas instituições psiquiátricas e por melhorias nas condições 
de vida dos pacientes e, assim, a trabalhar pela desospitalização (MUSSE, 2008). Os anos 70 igualmente evidenciaram um novo discurso: a Bioética (DINIZ, 2002) que, aliada à luta antimanicomial, possibilitou o surgimento de nomes como Basaglia que, na Itália, propunha a abolição do sistema hospitalocêntrico, denunciando os horrores que eram praticados em nome da razão. Basaglia, em sua visita ao Brasil, denunciou igualmente o sistema psiquiátrico brasileiro e ajudou a mudar a realidade no país. 0 final da década de 70 expressou uma série de lutas pelos direitos civis, sobretudo na área da saúde, tendo como pauta central as novidades trazidas pela Bioética em sua fase estadunidense, sendo ainda amplamente marcado pelo debate nacional acerca do teor do Decreto Presidencial de 1934 que permitia o recolhimento de paciente psiquiátrico a hospital mediante simples atestado médico (BRASIL, Decreto no 24.559/1934), face à necessidade de garantia da autonomia e da dignidade.

Dessa forma, com o tempo, com as lutas pelos direitos das pessoas com deficiência, com o adensamento das demandas por uma nova pauta ética na área da saúde - e com os avanços na área farmacêutica, sobretudo com a criação dos primeiros psicotrópicos (COELHO, 2014) - e atrelada a eles as crescentes indignações e denúncias do modelo de internação manicomial, cresceu, no país, um movimento que buscava o fim dos manicômios e a implementação do tratamento extra-hospitalar, que respeitasse os direitos dos internos de tal forma que a sua dignidade fosse entendida como elemento nuclear. Essa tendência ao tratamento ambulatorial do doente teve fortes influências do movimento da reforma psiquiátrica italiana e francesa, países que inovaram nessa abordagem (CUNHA, 2017).

Um dos primeiros estados brasileiros a se engajar em tal movimento foi Minas Gerais (ARBEX, 2013). Dessa maneira, foi criado em 1987, quase uma década após o início do movimento - ocorrido em 1978 -, o primeiro Centro de Atenção Psicossocial (CAPS), importante instituição substitutiva dos hospitais psiquiátricos. Dois anos mais tarde foi criado um projeto de lei (que viria a se tornar lei em 2001) com intento de regulamentar os direitos dos pacientes, a extinção progressiva dos modelos convencionais de tratamento e a sua inserção em um modelo terapêutico extra-hospitalar (SARRETA, 2005). 


\section{A REFORMA PSIQUIÁTRICA NO BRASIL: IMPLEMENTAÇÃO E EFEITOS}

Foi no cenário político oportunizado pelo processo de redemocratização do Brasil que, nos anos 1990, ocorreu um amplo debate envolvendo os diversos setores da sociedade civil sobre os direitos fundamentais das pessoas com deficiência e, especificamente, dos deficientes psíquicos. Dentre as exigências, se destacava a necessidade do reconhecimento da autonomia ético-jurídica dessas pessoas, coincidindo com a recepção propriamente dita e a reafirmação da essência do discurso bioético e de seus desdobramentos no Brasil. A propósito, foi com a promulgação da Constituição Federal de 1988, notadamente a partir do que prescreveu em seus artigos 3ํ, IV; 7º XXI; 23, II; 24, XIV; 37, VIII; 196, 203, IV; 208, III; $227, \S 1$, II, que se tornaram possíveis as mudanças mais efetivas na área da saúde mental.

Conveniente esclarecer as diversas fases pelas quais passou a composição de um conceito de deficiência, situação amplamente agravada quando se trata de deficiência psíquica em função da sua complexidade outrora mencionada, restando ainda para muitos uma sutil fronteira que subsiste na identificação dos pacientes com a condição de pessoa com deficiência (KENNETT, 2007). 0 fato induvidoso é que os anos 90 podem ser considerados como um marco na definição de deficiência a partir do modelo social e, desse modo, acarretou um início de esforços, sobretudo legislativos, de proteção das pessoas com deficiência, ampliando o âmbito de garantia e de proteção. Em termos gerais, a CF/88, com fulcro nos princípios gerais da dignidade da pessoa humana e da igualdade, proibiu toda e qualquer forma de discriminação e assegurou a diversidade como elemento constitutivo da sociedade brasileira no sentido de que sua pluralidade esteja amparada particularmente pelos princípios da responsabilidade e da solidariedade.

A CF/88, portanto, proscreveu todas as formas de discriminação, especialmente no tocante ao salário e aos critérios na admissão de trabalhador com deficiência; atribuiu competência comum da União, dos Estados e dos Municípios para cuidar da saúde e da assistência pública, bem como da proteção e da garantia das pessoas com deficiência; 
reservou cargos e empregos públicos para pessoas com deficiência na Administração pública; se obrigou à prestação da assistência social para assegurar a habilitação e a reabilitação das pessoas com deficiência e à promoção de sua integração à vida comunitária; se obrigou a oferecer atendimento educacional especializado às pessoas com deficiência, preferencialmente na rede regular de ensino; instituiu o dever da Família, da Sociedade e do Estado em favor da criança e do adolescente, de criar programas de prevenção e de atendimento especializado para as pessoas com deficiência física, mental ou sensorial, visando favorecer a reintegração social dessas pessoas mediante o treinamento para o trabalho e para a convivência e, desse modo, facilitar o acesso a bens e aos serviços coletivos com a eliminação de preconceitos e dos obstáculos arquitetônicos (NUSSBAUM, 2013).

Em se tratando de saúde mental, a repercussão desses preceitos constitucionais, segundo os dados do Ministério da Saúde, atingiram e continuam atingindo em média a 12 por cento da população brasileira, sendo esse o percentual da população brasileira que necessita de algum tipo de atendimento psiquiátrico, contínuo ou eventual (LOURENÇO,2010). Nesta quadra, imperioso é sublinhar alguns dos principais direitos constitucionalmente assegurados que afetam mais diretamente às pessoas com transtornos psíquicos no Brasil: o direito à vida e à igualdade, o direito a não discriminação, o direito à liberdade, o direito à saúde, o direito à educação, o direito ao trabalho, o direito à moradia, o direito à inclusão social, o direito ao convívio familiar e social, os direitos sexuais e reprodutivos, os direitos culturais e, sobretudo, o direito a receber o atendimento adequado ao seu quadro clínico, direito à privacidade, à honra e à intimidade, o direito ao livre desenvolvimento de sua personalidade, dentre outros (CIFUENTES, 2008; SARLET; MARINONI; MITDIERO, 2017; DE CUPIS, 1961).

Inconteste é a afirmação de que o direito mais elementar quando se trata da condição de deficiente psíquico é o direito ao diagnóstico. Ademais, a ONU já havia preconizado desde 1991, por meio da Carta de Princípios sobre a Proteção das pessoas acometidas por transtornos mentais e as melhorias da assistência à saúde mental, que o diagnóstico de um transtorno mental deve ser de natureza não discriminatória, pau- 
tado, portanto, em critérios internacionalmente aceitos como o CID- $10{ }^{1}$

0 profícuo debate acerca da saúde mental no Brasil do período pós-Constituição de 1988, intentava uma série de reformas drásticas das práticas e da assistência em saúde mental. Foi nesse cenário que surgiu a Lei no 10.216, em 06 de abril de 2001, também chamada de Lei da Reforma Psiquiátrica (LRP). Com a promulgação dessa lei passou a se reconhecer uma nova categoria de sujeitos na pespectiva do direito e das políticas públicas, porquanto os pacientes psiquiátricos passaram a ser conhecidos como novos sujeitos de direitos. A ideia era, por meio do empoderamento de tais sujeitos, fortalecer a identidade e a autonomia individual dos pacientes psiquiátricos no Brasil para que eles se tornassem protagonistas, emancipados e construtores de sua própria cidadania, inclusive das tratativas que intentavam a construção das diretrizes da LRP. Igualmente relevante foi a instituição da Rede de atenção psicossocial por meio da portaria no 3.088, de 23 de dezembro de 2011. Ainda em 2011 foi relevante o lançamento do Plano Nacional dos Direitos da Pessoa com Deficiência - PVSL - Viver sem Limite - que consistia em um somatório de ações na área da saúde, da assistência social, da acessibilidade, e da educação, intentando articular os diversos interlocutores no sentido de orientar, acompanhar e avaliar as políticas públicas voltadas para esse grupo populacional.

Destaca-se igualmente, nesse itinerário, a condenação do Brasil no Caso Ximenes Lopes, assassinado dentro de um estabelecimento psiquiátrico no interior do Estado do Ceará, cuja família recorreu ao Sistema Interamericano de Direitos Humanos. A Corte Interamericana de Direitos Humanos acolheu o pleito reconhecendo a responsabilidade e condenando o Estado brasileiro pelas violações praticadas pela instituição privada conveniada com o SUS. Consistiu no reconhecimento da responsabilidade objetiva do Estado em razão da violação do dever de cuidado para com os acometidos pela enfermidade psíquica que se encontravam sob a sua guarda. No caso referido, a Corte condenou o Brasil por violações ao Pacto de São José da Costa Rica, do qual o Brasil é signatário, quanto aos artigos $1^{\mathrm{o}}, 4^{\mathrm{O}}$ (direito à vida), 5을 (direito à integridade pessoal), $8^{\circ}$ (garantias judiciais) e 25 (proteção judicial). A condenação do Brasil foi nos seguintes termos: (a) promoção, em tempo razoável, de investigação 
e da sanção dos envolvidos no caso; (b) publicação no Diário Oficial do conteúdo da decisão da Corte; (c) realização de programas de capacitação profissional para servidores da área de saúde mental, e, por fim (d) indenização aos membros da família de Damião Ximenes Lopes, além do pagamento de todas as despesas provenientes dos processos na justiça brasileira e no exterior (SILVA, 2017).

A sentença da Corte Interamericana de Direitos Humanos sobre o caso de Damião Ximenes Lopes foi a primeira a abordar o tratamento cruel e discriminatório dispensado às pessoas portadoras de transtorno mental. 0 reconhecimento pelo Sistema Interamericano da precariedade a que estão submetidos os pacientes ampliou a jurisprudência internacional e fortaleceu, nacionalmente, o trabalho de denúncia das organizações do movimento anti-manicomial, no que diz respeito à violação de direitos humanos em estabelecimentos psiquiátricos (SANCHES, 2017). A condenação do Brasil foi o radical catalizador da aprovação e da implementação da LRP, que garante como direitos do portador de transtorno mental, dentre outros, ter acesso ao melhor tratamento do sistema de saúde, consentâneo às suas necessidades; tratamento humano, sendo vedado qualquer tipo de abuso; tratamento em ambiente terapêutico, preferencialmente em serviços comunitários, vedando-se a internação em instituições de caráter asilar e visando à reinserção do paciente na Sociedade (SILVA, 2017).

De modo geral, a Reforma propunha uma terapêutica em que o paciente interatuasse com a Sociedade, a fim de buscar a sua reinserção nela. De longe a reforma psiquiátrica não está plenamente implantada no Brasil, restando muito a ser discutido, pautado e implementado. De fato, um dos obstáculos é a fragilidade da efetivação do direito à saúde no âmbito municipal, a despeito da previsão constitucional, em particular tendo em vista a precariedade do SUS. Outros aspectos dessa fragilidade ocorrem devido a falta de estabilidade nas relações empregatícias no caso dos pacientes com comprometimento psíquico, agravadas em razão da aprovação da atual reforma trabalhista, e da falta de uma maior vinculação do setor privado ao teor dos direitos fundamentais de modo geral e em especial aos das pessoas com deficiência. Além disso, deve ser mencionada a restrição dos leitos psiquiátricos no Brasil, a falta de continuidade do 
atendimento adequado em saúde mental nas unidades de saúde básica e a ausência de acompanhamento terapêutico das famílias dos pacientes psiquiátricos. Simbólica e discriminatória é a persistente tendência à segregação dos pacientes psíquicos em relação aos demais pacientes e a falta de atendimento comum em hospitais públicos e particulares.

Outro grande impedimento ao avanço no tratamento extra-hospitalar é a significativa (a despeito de importantes avanços em se considerando o quadro pretério à LRP) ausência de políticas públicas eficazes, em conformidade com o teor do artigo $3^{\circ}$ do referido diploma legal, o que se deve em grande medida à resiliência de uma cultura da internação arraigada na sociedade, tanto para os pacientes com transtornos mentais quando para os usuários de drogas. A sociedade brasileira, em rigor, tem medo de lidar com seus desviantes. Trata-se de medo, de intolerância, de ignorância e de despreparo em relação a qualquer tipo de comportamento que se situe na esfera de um desvio padrão. Grosso modo, tanto a coletividade quanto as famílias ainda acreditam que qualquer pessoa comportalmente diferenciada deva ser internada. Há, nesse sentido, uma grande dificuldade em se quebrar paradigmas preconceituosos a respeito da natureza do doente, inserindo-o em uma percepção integral. O isolamento e a manutenção compulsória da pessoa em uma instituição gera, em geral, a cronificação de sua deficiência, de seu transtorno, da sua compulsão e, nesse sentido, afeta, na maioria dos casos, definitivamente as suas chances de retorno à vida social.

Urge, dessa maneira, relembrar a importância da aproximação da Bioética da esfera pública, principalmente no que toca à elaboração de pautas e de agendas para a execução de politicas públicas (CAMPBELL, 2012). Essa aproximação que oportuniza o diálogo entre os gestores públicos, a sociedade civil e os bioeticistas, em especial os voltados à abordagem da Bioética da proteção, tem se mostrado frutífera no que afeta à ponderação de interesses diversos e à alocação de recursos. Apesar das críticas em razão de uma tendência ao paternalismo, essa corrente da Bioética afirma o dever do Estado em assumir obrigações sanitárias em uma perspectiva de proteção, ou seja, em uma abordagem a partir de uma ética da responsabilidade social correspondente. Embasa-se em uma ética da assimetria, a qual se define pela existência de dois polos 
distintos em que um deve assumir a responsabilidade de cuidar do outro na medida de sua vulnerabilidade. Importa sublinhar o seu viés coletivo, vez que cabe ao Estado, na qualidade de único ente político habilitado, proporcionar a proteção dos mais fracos (KOTTOW, 2005).

Merece igual ênfase o conteúdo da Declaração Universal de Bioética e Direitos Humanos que, em 2005, já afirmava a necessidade de ponderação a partir da autonomia e dos limites do consentimento em casos de terapêutica voltada para pacientes psiquiátricos. Consiste em um documento pautado no conceito de vulnerabilidade como condição universal produzido pelo Conselho de Organizações Internacionais de ciências médicas. Considera-se o indivíduo vulnerado em sua cognição e em sua esfera emocional de forma a possibilitar a produção de sua própria fala, embora suas capacidades sejam mitigadas pelo transtorno psíquico. Para tanto, recomenda-se a aplicação dos princípios bioéticos, sobretudo o da beneficência e o da não maleficência em um contexto de justiça que estruture um Projeto Terapêutico Singular. A partir desse documento houve o estabelecimento de uma agenda mundial para o século XXI, perpassando as questões sociais e políticas e, assim, expandindo a atenção para os países em desenvolvimento,e.g., os latino-americanos.

Em consonância, destaca-se o teor da Convenção Americana de Direitos Humanos, Pacto de São José da Costa Rica, que, em seu artigo $5^{\circ}$ dispõe que: "Toda pessoa tem o direito de que se respeite sua integridade física, psíquica e moral." Aduziu, igualmente, que toda pessoa deve ser tratada com o respeito devido à dignidade inerente ao ser humano. A Convenção internacional sobre os direitos das pessoas com deficiência, por sua vez, destacou a condição de pessoa como o ponto capital na esfera de proteção, enaltecendo a necessidade do respeito à autonomia individual, à dignidade, à plena e efetiva participação e inclusão na Sociedade, consubstanciada na igualdade de oportunidades e no reconhecimento da deficiência como uma das características da condição humana. Propício é relembrar o teor do Relatório Mundial sobre a Deficiência, de 2011, no qual a OMS - Organização Mundial de Saúde e o Banco Mundial em razão das metas para o desenvolvimento do milênio reafirmou a existência da deficiência como uma condição da pessoa humana, rechaçando qualquer espécie de discriminação e reafirmando ainda a importância de se tratar 
do tema em razão do envelhecimento populacional e da perda de algum tipo de funcionalidade, recomendou ações e providências de cuidado e de amparo na assistência no âmbito local, estadual e nacional.

A Lei no 13.146 , sobretudo no que tange aos artigos $2^{\circ}$ e $4^{\circ}$, regulamentou o cenário brasileiro, e.g., ao estabelecer o conceito de deficiência, modulando-o em função da igualdade de oportunidades e ao direito à não discriminação. Merece grifo em relação às estratégias de desinstitucionalização, a Lei no 10.708, de 31 de julho de 2003, que instituiu o auxílio-reabilitação psicossocial para pacientes acometidos de transtornos mentais egressos de internações. Interessa ainda salientar o teor das portarias no 3.088/11, que instituiu a Rede de atenção psicossocial e a de no 2.840/2014, que trata da criação do programa de desinstitucionalização no âmbito do SUS - Sistema Único de Saúde. Evidencia-se, destarte, a coincidência dos caminhos em busca do empoderamento dos pacientes percorridos pela Bioética e pelas lutas das entidades e das associações que visam a afirmação dos direitos das pessoas com deficiência, máxime das pessoas com deficiência psíquica no Brasil.

\section{A CONVENÇÃO DA ONU SOBRE OS DIREITOS DAS PESSOAS COM DEFICIÊNCIA E A LEI BRASILEIRA DE INCLUSÃO DA PESSOA COM DEFICIÊNCIA - LEI No 13.146/2015}

Muito embora os problemas ligados à discriminação e exclusão das pessoas com deficiência tenham sido enfrentados pela CF/88 e em boa parte já objeto de análise pela dogmática jurídico-constitucional, ${ }^{2}$ a Convenção sobre os Direitos das Pessoas com Deficiência (doravante CDPD), aprovada pela ONU em 2006, e incorporada ao direito interno brasileiro pelo Decreto no 6.949/2009 e pelo Decreto Legislativo no $186 / 2008$ representa um novo marco normativo, ético e jurídico, tanto na perspectiva do direito internacional, quanto para o direito interno, afirmando-se como dos mais relevantes documentos em matéria de direitos humanos, ainda mais mediante uma articulação produtiva com 0 direito constitucional e com os direitos fundamentais, encetando sérios influxos sobre o direito privado. 
A partir daí, em conformidade com a CDPD, a discriminação sofrida pelas pessoas com deficiência consiste em qualquer diferenciação, exclusão ou restrição baseada em deficiência cujo resultado seja toda e qualquer espécie de limitação de acesso a direitos e a garantias, bem como as diversas formas de políticas de reconhecimento de sua singularidade e, inclusive, à distribuição de bens e de recursos. Portanto, a alteração do padrão comportamental excludente só poderá ocorrer se, como outrora afirmado, for pautado em políticas públicas (MARMELSTEIN, 2013) que objetivem desde o esclarecimento, a educação até às intervenções mais radicais que propiciem alterações substanciais na vida cotidiana e nos marcos normativos afim de que as pessoas deficientes gozem seus direitos.

Para tanto, o teor dessa Convenção adicionou ao legado do modelo social à contribuição (SAFFIOTI, 2009) feminista (DINIZ, 2003), além de adicionar vivamente a recomendação da ótica bioética, por meio da superação do paradigma biomédico. Trata-se, portanto, de uma modalidade de percepção da deficiência a partir de uma concepção sociológica, mas, igualmente como expressão de um conceito eminentemente político (RIOS, 2010). O modelo social se pauta preponderantemente em dois pontos: 1- A deficiência em si não poder justificar a desigualdade e a exclusão que ainda se verifica em relação aos deficientes, condizendo, nesse sentido, com a proposta de separação entre os conceitos de lesão e de deficiência; 2 - Uma vez que se trata de um conceito sociológico e igualmente politico, a abordagem deixaria de ser individual, personalizada e biomédica no sentido de uma tragédia pessoal ou de castigo divino para ser pensado na forma de objeto para a criação de políticas públicas que visem a transformação de todas as espécies de padrões sociais excludentes, transferindo a responsabilidade acerca da inclusão para o Estado em parceria com a sociedade civil (DINIZ, 2003).

0 modelo social, em apertada síntese, operando uma clivagem no conceito de deficiência, buscou superar (DINIZ; SANTOS, 2010) o chamado modelo biomédico (RODRIGUES, 1999) da deficiência que buscava moldar a pessoa deficiente a um padrão social, mental e físico. De todo modo, deve-se ressaltar que esse modelo biomédico recria e, especialmente, reforça as estruturas de discriminação e de intolerância. Com efeito, um dos legados mais importantes desse modelo social 
foi a compreensão da deficiência em uma perspectiva coletiva que se projeta para a pluralidade, para a igualdade, para a tolerância e para a diversidade. Outra herança fulcral é a consciência de que cabe a todos, solidariamente, a retirada das barreiras sociais, intelectuais, culturais e arquitetônicas que separam todas as pessoas, deficientes ou não. Consequentemente, diz-se que houve a tentativa de neutralização do aspecto estigmatizante da concepção de deficiência. Pode se inferir que um dos maiores desafios ainda é, em uma perspectiva de justiça, retirar a questão da deficiência da esfera privada para a esfera pública e, assim, forjar um novo padrão comportamental, mas sobretudo normativo. Segundo o último Censo cerca de 24 por cento da população brasileira sofre algum tipo de deficiência (G1, 2010).

Note-se que o Brasil ratificou com força de emenda constitucional a CDPD, que passou a integrar o bloco de constitucionalidade interno, servindo de parâmetro, portanto, tanto do controle de constitucionalidade dos atos do poder público nacional, quanto do assim designado controle de convencionalidade (SILVA, 2016). Em decorrência disso foi promulgada a Lei no 13.146/15, vulgarmente conhecida como o Estatuto da Pessoa com Deficiência (doravante EPD), visando a concretização das ideias de igualdade, de dignidade, de tolerância, de cidadania e de liberdade de forma a tornar efetiva a inclusão das pessoas com deficiência em todos os âmbitos da vida nacional. Trata-se de um fruto tanto da recepção da supramencionada CDPD quanto do seu protocolo facultativo, ratificados pelo Congresso Nacional em 2008 e promulgados por meio do Decreto no 6.949, de 2009.

$\mathrm{O}$ EPD alinhou-se à CDPD e considerou preliminarmente a pessoa com deficiência como aquela que possui um impedimento de longo prazo que pode obstruir a participação plena e efetiva em igualdade de condições com as demais pessoas, alinhando a perspectiva legal com o conceito advindo do modelo social. Afirmou a ideia ampla de impedimento que engloba desde os de natureza física, intelectual, sensorial até mental, sublinhando o mérito do atendimento multiprofissional e interdisciplinar tanto para a avaliação da deficiência quanto para o acompanhamento da pessoa com deficiência.

Levando a sério os deveres de promover a inclusão social, para além da proibição estrita de discriminação das pessoas com deficiência, o EPD 
efetivou mudanças significativas em alguns institutos do direito privado, dentre eles, a interdição, o casamento e a curatela, na medida em que provocou uma alteração profunda na antiga teoria das incapacidades mediante a revogação de todos os incisos do artigo $3^{\circ}$ do Código Civil brasileiro. Sinteticamente, não há mais incapacidade absoluta para pessoa que seja maior de idade na previsão normativa, esvaziando, desse modo, o instituto da interdição absoluta no Brasil. Singular realce merece o teor do artigo $6^{\circ}$ do Estatuto da Pessoa com Deficiência. E, assim, apenas em casos excepcionais, previstos no novo artigo $4^{\circ}$ do diploma civil pode se mencionar o enquadramento de pessoas com deficiência em situação de incapacidade relativa, exempli gratia, casos de drogadição e de alcoolismo.

Com base no que se poderia designar como uma nova plataforma jurídica para as incapacidades, alguns elementos, todavia, ainda estão em fase de visível problematização, como é o caso dos psicopatas, especialmente a partir da entrada em vigor do Novo Código de Processo Civil. 0 artigo 26 do EPD e seu parágrafo único, por sua vez, são dignos de nota, pois tratam dos casos de violência ou de suspeita de violência praticada contra pessoa com deficiência, definindo como violenta qualquer ação ou omissão, praticada em local público ou privado, que acarrete em morte, em dano ou sofrimento físico ou psicológico. Outro ponto crucial é o limite da atuação do poder público no que toca à autonomia existencial dos pacientes psiquiátricos Além disso, precisamente pela sua essencialidade para o presente artigo, está a situação dos dependentes químicos, para os quais se coloca o problema da própria inclusão no grupo das pessoas com transtornos psiquiátricos, para efeitos de aplicação da legislação, em particular da LRP no que diz com as internações compulsórias. O que se tornou, entretanto, inquestionável foi a prioridade da tutela assegurada às pessoas com deficiência, mormente no que tange à concretização do direito à habilitação e à reabilitação. 


\section{O PROBLEMA DA LEGITIMIDADE JURÍDICA DAS INTER- NAÇÕES COMPULSÓRIAS NA LRP NA PERSPECTIVA DOS DIREITOS HUMANOS E FUNDAMENTAIS E O CASO DAS PESSOAS COM DEPENDÊNCIA QUÍMICA E ALCOOLISMO: UMA ANÁLISE CRÍTICA DO CASO DA “CRACOLÂNDIA" EM SÃO PAULO}

Antes de avançarmos em termos de uma avaliação mais geral, calha recordar que toda e qualquer medida adotada e implementada pelo poder público (e mesmo por atores privados), há de observar o marco normativo constitucional e legal (inclusive e em especial - para o caso - da LRP) sempre iluminado pelo dever de respeito, de promoção e de proteção da dignidade de cada pessoa humana e dos direitos humanos e fundamentais.

Muito embora se cuide de uma questão infelizmente verificada, em maior ou menor intensidade e visibilidade, em vários lugares no Brasil, a situação da assim chamada cracolândia na cidade de São Paulo tem ocupado um triste lugar de destaque. Especialmente desde 1990 a população da cidade de são Paulo vem assistindo os desdobramentos da ineficiência dos poderes públicos, aliada a uma verdadeira epidemia do crack, no sentido de transformarem a região central da Luz no que passou a se designar de uma cracolândia. Em rigor, trata-se de um reflexo do problema da drogadição que atingiu particularmente as metrópoles do Brasil, vez que, o país é o segundo maior mercado no Mundo de cocaína e o maior de crack. A drogadição passou a ser cada vez mais um premente e grave problema de saúde pública, de segurança e de educação no mundo atual, que impõe e exige ações intersetoriais eficazes e urgentes (WARSCHAUER, 2014), mediante a articulação de diversos órgãos, setores e saberes para o enfrentamento de situações complexas, sobretudo na área da saúde. Para se ter uma noção da gravidade do problema, o INPAD - Instituto Nacional de Ciência e Tecnologia para Políticas Públicas do Álcool e outras drogas $^{3}$ divulgou que $4 \%$ da população brasileira adulta já experimentou cocaína e seus derivados e entre os adolescentes o percentual é de $3 \%$.

No caso do crack, a euforia, a sensação de poder, a alta autoestima e a perda de apetite são alguns dos sintomas imediatamente produzi- 
dos no corpo e na mente dos usuários. Em geral, quinze minutos após ter sido inalado, iniciam os sinais de abstinência, gerando um alto grau de lesividade ao organismo e um quadro de rápida dependência aguda. Não se pode afirmar, contudo, que apenas as massas humanas em estado de drogadição transformaram a região da luz em cracolândia. De fato, a negligência dos poderes públicos foi oportunizando espaços para as pessoas invisibilizadas e negligenciadas, gerando altos índices de exclusão social. Em 2007, por exemplo, a Prefeitura de São Paulo, iniciou um processo de demolição de vários prédios, deixando a região em ruínas. Sob os auspícios de um programa ubanístico chamado Nova Luz, as intervenções tem sido ao longo dos anos efetuadas ao arrepio do reconhecimento da ZEIS, isto é, áreas localizadas em zonas especiais de interesse social, cuja população de baixa renda deve ser protagonista das alterações empreendidas mediante participação do conselho gestor. Em maio do mesmo ano, ocorreu uma ação policial anti-tráfico particularmente violenta em que se empreendeu a desapropriação de imóveis, a internação em massa de dependentes químicos, a interdição de alguns, a demolição de prédios ocupados por pessoas, a remoção de pessoas à força para posterior avaliação médica, resultando na prisão de 53 pessoas, 51 por tráfico de drogas, além de uma série de violações aos direitos humanos e fundamentais de aproximadamente 2.000 pessoas que perambulavam diariamente entre as ruas Helvetia e Cásper Libero, no bairro Santa Efigênia. Tudo isso em manifesto desacordo com a recomendação dos protocolos que incluem prioritariamente abordagens de dissuasão amigável das pessoas com dependência química em uma perspectiva de políticas públicas avessas ao mero higienismo, visando a beneficência, a não maleficência e assegurando a justiça aos usuários em um contexto de valorização de sua autonomia.

Tal quadro, seguiu ocorrendo e desembocou em uma nova operação para promover a desocupação em massa de prédios e de logradouros da região da assim chamada Cracolândia, em 21 de maio de 2017, amplamente noticiada e novamente objeto de acirrada controvérsia, dentre aplausos e críticas. Muito embora nos episódios narrados as medidas tomadas pelo poder público tenham sido de natureza diversa, exigindo avaliação em separado até mesmo pelo fato de diverso eventual impacto sobre os 
direitos humanos e fundamentais das pessoas afetadas, o foco da presente análise, na perspectiva da Bioética, da LRP, da CDPD e do EPD, bem como do princípio da dignidade da pessoa humana e dos direitos e garantias fundamentais ancorados na CF/88, é o da legitimidade da utilização do instrumento das internações compulsórias no caso da Cracolandia em São Paulo, e, de modo geral, para internações compulsórias em caráter coletivo ou individual de pessoas com narcodependência.

Assim, em uma primeira aproximação, merece grifo a concepção de que o abrigamento compulsório, sob o viés tanto da Bioética quanto do atual padrão normativo, somente se justifica após o exaurimento de todas as tentativas extrahospitalares em uma conjuntura de um projeto terapêutico, em que seja considerada a subjetividade, a singularidade e a visão de mundo do paciente psiquiátrico. As intervenções devem superar o padrão saúde-doença e, ampliando a ação para além da sintomatologia aparente, possibilitar as condições reais de reinserção na vida em comunidade.

Enfatiza-se que a Organização Pan-Americana da Saúde (OPAS) - órgão de representação da OMS no continente americano -, por meio de nota técnica divulgada em maio de 2013 , teceu críticas à priorização conferida à internação compulsória para o tratamento de usuários de drogas no Brasil. Por meio da referida nota, a OPAS considera inadequada e ineficaz o uso da internação involuntária ou compulsória como principal meio para o tratamento da dependência de drogas. Reconheceu, ainda, que a priorização do internamento obrigatório, como medida extrema que é, encontra-se na "contramão do conhecimento científico sobre o tema" e pode "exacerbar as condições de vulnerabilidade e exclusão social dos usuários de drogas” (DOURADOSAGORA, 2013).

Finalmente, a ausência de políticas públicas efetivas voltadas para o apoio das famílias das pessoas com transtornos mentais (e, para o caso ora em exame, das pessoas com dependência química ou mesmo alcoólica) não pode servir de justificativa para as internações obrigatórias, compulsórias ou involuntárias. Na realidade, no que se refere ao apoio às famílias há um completo vácuo nas ações do poder público, resultando não somente em um substancial esvaziamento da efetividade da LRP, mas também em um quadro de violação da própria CF, do EPD e da CDPD, o 
que, contudo, não poderá aqui ser objeto de desenvolvimento, visto que o foco são as internações compulsórias.

A internação obrigatória (expressão que aqui se utiliza como gênero, abarcando, nessa fase, as modalidades compulsória e involuntária), contudo, nem sempre tem sido apropriadamente manejada, seja no âmbito dos serviços de saúde, seja na esfera jurídica, o que se deve a uma série de fatores que desafiam uma maior reflexão e impõe o enfrentamento de uma série de perplexidades, jurídicas e práticas, consoante, aliás, ficou evidenciado no caso da cracolância ora comentado (MONTEIRO, 2016).

Um primeiro problema diz respeito ao escopo e o alcance das internações de caráter cogente (no episódio da cracolandia utilizou-se o expediente da internação compulsória) estabelecidas pela LRP. Dentre os principais vetores da legislação referida, está a proibição de toda e qualquer discriminação das pessoas com transtornos mentais, além de privilegiar o acompanhamento e o tratamento no núcleo familiar e evitar ao máximo a institucionalização de tais pessoas, de modo a assegurar a sua integração na vida social e familiar. Ademais disso, a Lei da Reforma Psiquiátrica enfatiza o respeito à autonomia da pessoa com transtornos mentais e aposta no caráter excepcional das internações involuntárias (aqui designadas de obrigatórias).

Especificamente no que diz respeito ao caso, a internação psiquiátri-

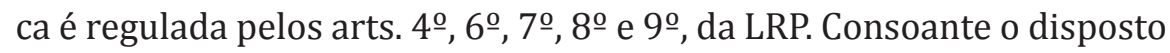
no art. $4^{\circ}$, caput, a internação psiquiátrica, em qualquer das modalidades, somente se mostra cabível quando os recursos não hospitalares forem tidos como insuficientes e houver risco à integridade física, à saúde ou à vida dos portadores de transtorno mental ou a terceiros. A situação de perigo concreto deve estar prevista em laudo médico circunstanciado, caso contrário, torna-se incabível a obrigatoriedade de internação do paciente (art. 6oㅗ caput). Em havendo necessidade do internamento, este deverá buscar a cessação do estado de perigo com a consequente reinserção social do paciente em seu meio (art. 4, §§ $1^{\circ}$ e $2^{\stackrel{o}{ } \text { ). }}$.

De acordo com a LRP são três as modalidades de internação psiquiátrica (art. 6, § único, incisos I a III), quais sejam: voluntária, involuntária e compulsória. Na internação voluntária pressupõe-se o consentimento do paciente, que deverá assinar uma declaração atestando sua escolha por 
este tipo de tratamento (art. 7ํ, caput). A internação involuntária dá-se sem o consentimento do usuário e a pedido de terceiro, sendo que seu término somente ocorrerá por solicitação escrita do familiar ou responsável legal ou ainda quando houver manifestação do médico responsável pelo tratamento (art. 8, § $2^{\circ}$ ). Neste caso, tanto a internação como a alta do paciente devem ser comunicadas no prazo de setenta e duas horas ao Ministério Público estadual, (art. 8oㅗ $§ 1^{\circ}$ ). Restando configurado que a internação involuntária não atende aos requisitos legais e cuidando-se de restrição ao direito de liberdade, cabível a impetração de habeas corpus, conforme já decidiu o Superior Tribunal de Justiça. (STJ, HC 35301/ RJ, Rel. Nancy Andrighi, j. 03.08.2004).

Já a internação compulsória (art. 6oㅗ § único, inciso III), é decorrente de ordem judicial, necessariamente, amparada em laudo médico que descreva de forma detalhada a situação de perigo concreto. Será utilizada quando não for possível, ou insuficiente, o tratamento não hospitalar e houver probabilidade de risco à integridade física, à saúde ou à vida da pessoa com transtorno mental ou a terceiros. Tal tipo de internação consiste em um "procedimento judicial cautelar ou de mérito", ao qual são aplicáveis, segundo entendimento corrente, as mesmas normas relativas à internação psiquiátrica involuntária (PINHEIRO, 2010).

Note-se que STJ já decidiu - sem nenhum questionamento sobre a constitucionalidade da medida - pela possibilidade do internamento obrigatório, entendendo que a medida, excepcional, objetiva resguardar a própria saúde e mesmo a vida da pessoa com transtorno mental e mesmo de terceiros, não tendo por escopo a privação da liberdade em si, mas sim, fazer valer o direito fundamental à vida e à saúde (STJ, HC 130.155/SP, Rel. Min. Massami Uyeda, j. 04.05.2010). Frise-se, portanto, a necessária observância de um devido processo formal e material para legitimar as internações obrigatórias (sejam compulsórias, sejam involuntárias, nos termos da LRP), o que também deverá balizar - em se admitindo tal hipótese!!! - eventuais internações cogentes em casos de dependência química ou alcoolismo, que não foram objeto de previsão legal específica.

O que deve ser destacado, é que a eventual aplicação da LRP para dependentes de drogas e alcoolistas, apenas poderia - em sendo esse o caso - ser admitida em restando comprovado, mediante laudo médico- 
-psiquiátrico circunstanciado, que da dependência química ou alcoólica tenham resultado graves transtornos mentais, equivalentes aos abarcados pela LRP, mas não apenas com base na demonstração da dependência em si. Importa ainda destacar a necessidade do cumprimento dos objetivos da LRP que, em síntese, asseguram ao indivíduo psiquicamente vulnerado a sua autonomia, embora limitada, e, em especial, a sua dignidade.

Além disso, resulta evidente que a LRP e o instituto da internação compulsória são insuscetíveis de serem utilizados para internações em massa, ou mesmo para legitimar a condução coercitiva de grupos de pessoas para serem submetidas a exame médico-psiquiátrico, simplesmente pelo fato de estarem localizadas em zonas com concentração de pessoas narcodependentes e/ou alcoolistas, inadequação que não resta suprida pelo simples fato de ter sido judicialmente autorizada, até mesmo pelo fato de o Poder Judiciário também estar vinculado aos direitos humanos e fundamentais e ao princípio da dignidade da pessoa humana. Ademais, a LRP e os instrumentos das internações, em especial a compulsória e a involuntária, devem ser compreendidos e aplicados em estrita sintonia com a CDPD, com o EPD e com a constelação de direitos e de garantias contempladas na CF/88, o que definitivamente não foi o caso da operação empreendida pelo poder público paulista neste episódio da evacuação da cracolândia.

\section{CONCLUSÃO}

À vista do exposto, a primeira consideração em caráter conclusivo é a de que não há como agasalhar qualquer medida que tenha por escopo uma "conveniente limpeza das ruas e dos lares", isolando pura e simplesmente as pessoas com dependência química e alcoólica, usando para tanto o instrumento da internação psiquiátrica obrigatória. Assim, em caráter de síntese, a internação obrigatória (aqui- cumpre repisar - compreendida como gênero!), além de assumir caráter excepcional, demanda adequada justificação médico-psiquiátrica, pressupondo a existência de transtorno mental grave (que poderá, ou não, decorrer do uso abusivo de drogas, álcool e congêneres, mas deverá sempre consistir em transtorno mental 
grave!) cujo tratamento seja inviável do ponto de vista de sua eficácia sem a medida coercitiva, o que, por sua vez, corresponde ao requisito do menor sacrifício, ou seja, da exigibilidade, que integra o teste de proporcionalidade. Além disso, a medida pressupõe que esteja em causa o grave comprometimento da própria integridade física e mental da pessoa que se busca internar e a salvaguarda de direitos fundamentais de terceiros.

Recolocadas tais premissas e retornado ao recente caso das medidas tomadas (depois corretamente suspensas) em relação aos ocupantes da assim chamada "Cracolandia", não há como transigir com o fato de que o instrumento da internação obrigatória em hipótese alguma poderá ser utilizado de modo generalizado, em especial para internações em massa e/ou em caráter preventivo de dependentes químicos ou outras situações em que não esteja configurada, em concreto, grave distúrbio mental, a reclamar, para a própria proteção do paciente e de terceiros, ademais se inexistentes outras alternativas, sua temporária e controlada internação, assegurando-se sempre um tratamento humano e condigno em todo e qualquer caso e em sintonia com as exigências da ética, da Bioética e da medicina.

É evidente, por outro lado, a configuração de um dilema de difícil solução jurídica e prática, mas cuja dificuldade e complexidade não pode - em hipótese alguma - ser objeto de solução simplista, autoritária, invasiva (para não dizer violenta) e generalizada, sequer reduzida às por si só já graves - internações, mas também acompanhada da evicção forçada de grupos de pessoas. Em primeiro lugar não se pode presumir pura e simplesmente que centenas ou mesmo mais pessoas sejam viciadas em drogas pesadas (em especial o crack) pelo fato de conviverem e circularem em local onde se verifica alta concentração de pessoas dependentes. Da mesma forma não se pode partir da presunção de que tais pessoas (mesmo se houvesse indicação individualizada) estejam em situação de risco efetivo em termos de sua saúde e de vida ou que estejam concretamente colocando em risco real a vida e integridade de terceiros, ainda mais de modo generalizado. Acrescenta-se a isso que não se pode de modo generalizado ter elementos indicativos de que os dependentes químicos estejam com sua saúde mental comprometida (sejam diagnosticados com alguma espécie de transtorno mental), indicativos 
concretos e individualizados sem os quais uma internação compulsória, mas também uma apresentação coercitiva para avaliação médica são categoricamente vedados pela ordem jurídica nacional e pelos critérios do direito internacional dos direitos humanos.

Por outro lado - e nisso reside o dilema - o Estado está vinculado a deveres de proteção da dignidade, da saúde e da vida tanto de dependentes químicos, quanto de terceiros. Assim, sem que se questione as evidências de que em geral os moradores da "cracolândia" estejam vivendo em estado de manifesta indignidade e risco, bem como levando em conta que as pessoas que ali se encontram muitas vezes lá estão em virtude de sua condição (dependência) físico-psíquica, mas também econômica e social, o fato de o poder público ter a obrigação de sanar o problema não serve de autorização para fazê-lo de qualquer modo, ainda mais mediante atropelo de direitos humanos e fundamentais e correspondentes garantias.

A situação se agrava diante da complexidade (DINIZ, 2010) do problema. 0 recurso a uma solução simplista e generalizada (tal como protagonizada pelo poder público paulista), ademais de autoritária e invasiva, além de juridicamente inadmissível, ainda mais quando o Estado (aqui em sentido geral) tanto se manteve distante e mesmo ausente, de certo modo permitindo a potencialização do problema. As medidas a serem tomadas deveriam ter sido cuidadosamente avaliadas, graduais e baseadas prevalentemente em uma presença amiga do poder público, agindo de modo pedagógico e persuasivo, recorrendo a expedientes mais rigorosos (como a internação e/ou apresentação coercitiva para avaliação) em casos individualizados e escorados em evidências concretas, mediante o devido controle jurisdicional e respeitado o alcance da legislação.

Por mais que isso se revele díficil de ser executado, inclusive por demandar um tempo maior, o caminho há de ser esse, e não um processo que mais se assemelha a uma medida de higienização coletiva. 0 que se faz necessário é incrementar os debates, sobretudo na perspectiva plural e interdisciplinar oferecida pela bioética, aperfeiçoar a legislação e as instituições, mas acima de tudo se faz cogente o devido respeito e a consideração de que a dignidade da pessoa humana, de todas as pessoas, inclusive as que circulam na Cracolândia, reclamam. 
Nesse aspecto, particular importância adquire o adensamento da Bioética no Brasil, principalmente na elaboração e na execução de políticas públicas na área da saúde, em especial as que afetem às pessoas com deficiência. Assim, os direitos das pessoas vulneráveis devem ser assegurados visando o fim da marginalização dessas pessoas e à (re)inclusão destas na vida coletiva. ${ }^{4}$ A propósito, para garantir e para assegurar a igualdade, não basta apenas proibir a discriminação, mediante legislação repressiva. São essenciais as estratégias promocionais capazes de estimular a inserção e a inclusão desses grupos socialmente vulneráveis nos espaços sociais (PIOVESAN, 2010). 0 reconhecimento da dignidade humana das pessoas com deficiência defronta-se com a sua inexorável realidade de exclusão social, política, econômica e cultural. A exclusão dessas pessoas significa verdadeira violação a sua dignidade humana, na medida em que só faz crescer a sua invisibilidade ante o meio social, apartando-as cada vez mais deste último (MADRUGA, 2013).

0 ser humano é um ser social. Apartá-lo desse meio significa causar mal a ele, pois constituir laços familiares, de amizades, de sociedade é fundamental para o sadio desenvolvimento do ser. Enclausurar os doentes em instituições que mais se assemelham a presídios significa quebrar seus laços sociais, piorando, assim, seu estado de saúde e emocional (DALLARI, 1998). Excluir não resolve o problema da doença mental, sequer da drogadição ou do alcoolismo. Pelo contrário, o mero encarceramento de tais pessoas agrava a sua doença e abre cada vez mais o leque de possibilidades para as violações ao princípio da dignidade da pessoa humana.

Evidencia-se que há atualmente a precariedade e a ineficiência de políticas públicas que, não somente assegure o direito à saúde em sua integralidade, mas que igualmente promovam o enfrentamento da questão da saúde mental e da drogadição no país. Isto posto, é necessário que a Sociedade desmistifique alguns (pre)conceitos e que possa auscultar os índices de aumento do acometimento de doenças mentais, de alcoolismo e da dogradição como sintomas de sua própria situação de adoecimento social, retirando a questão da esfera privada e reposicionando-a cada vez mais na esfera pública para tornar todos merecedores de políticas públicas pautadas na perspectiva da Bioéti- 
ca, notadamente da Bioética de proteção, e não no esquecimento, na invisibilização, no enclausuramento e no descaso.

\section{NOTAS}

1 In:http://www.dhnet.org.br/direitos/sip/onu/deficiente/protec.htm. Consulta em: 09.jun.2017.

2 "Essas questões se relacionam diretamente à dogmática constitucional do princípio da igualdade no direito brasileiro. 0 direito brasileiro dispõe de uma lista exemplificativa de critérios proibidos de discriminação e de extenso rol de direitos fundamentais, ainda que não exaustivo. Juntos, tais critérios e direitos proveem proteção contra discriminação fundada em condições pessoais (idade) e em escolhas e condutas (convicção filosófica e expressão artística). Nesse quadro, o reconhecimento da proibição de discriminação por deficiência é incontestável" (RIOS, 2010).

3 Disponível em: <www.inpad/lenad.org.br>. Acesso em: 07 ago. 2017.

4 Do mesmo modo assegura o Art V da Declaração Universal dos Direitos Humanos (1948): Ninguém será submetido à tortura, nem a tratamento ou castigo cruel, desumano ou degradante.

\section{REFERÊNCIAS}

ARBEX, Daniela. Holocausto Brasileiro. 4. Ed. São Paulo: Geração Editorial, 2013.

ARENDT, Hannah. A condição humana. Rio de Janeiro: Forense Universitária, 2003.

CAMPBELL, A.T.. Bioethics in public square: reflections on the how. J. Med. Ethics, 2012, (38), 439-41.

CIFUENTES, Santos. Derechos personalíssimos. 3. ed. Buenos Aires: Astrea, 2008.

COELHO, Fábio Roberti. 0 que são psicotrópicos. Clínica Terapêutica Cantareira. Disponível em: <http://www.ctcantareira.com.br/substancias/o-que-saopsicotropicos.html>. Consulta em: 17.abril.2016.

COMISSÃO INTERAMERICANA DE DIREITOS HUMANOS (CIDH). Convenção americana sobre os direitos humanos: assinada na Conferência especializada interamericana sobre direitos humanos, San José, Costa Rica, em 22 de novembro de 1969. Disponível em: <http://www.planalto.gov.br/ccivil_03/ decreto/1990-1994/anexo/and678-92.pdf> . Acesso em: 15 fev. 2017.

CORTE INTERAMERICANA DE DIREITOS HUMANOS. Caso Ximenes Lopes vs . Brasil. Sentença de 04 de julho de 2006. Mérito, Reparações e Custas. Disponível em: <http://www.corteidh.or.cr/docs/casos/articulos/seriec_149_por.pdf> . Acesso em: 05 fev. 2017. 
MELO, Giane Alves de; CUNHA, Assis. Saúde Mental: Luta Antimanicomial, Reforma Psiquiátrica e CERSAMs. Disponível em: <http://www.webartigos. com/artigos/saude-mental-luta-antimanicomial-reforma-psiquiatrica-ecersams/11430/\#ixzz2w68jnY62> . Acesso em: 18 fev 2017.

DALLARI, Dalmo de Abreu. Elementos da teoria geral do estado. 2. ed. São Paulo: Saraiva, 1998.

DE CUPIS, Adriano. Os direitos da personalidade. Lisboa: Livr. Morais Ed., 1961.

DINIZ, Débora. Modelo social da deficiência: a crítica feminista. Série Anis. Brasília: Letras Livres, 2003.

DINIZ, Debora; SANTOS, Wederson. Deficiência e direitos humanos: desafios e respostas à discriminação. In: DINIZ, Debora; SANTOS, Wederson (Org.). Deficiência e discriminação. Brasília: Letras Livres, p. 09-17, 2010.

DINIZ, Maria Helena. 0 estado atual do Biodireito. 7. ed. São Paulo: Saraiva, 2010.

DOURADOSAGORA. Priorizar internação compulsória para tratamento de drigas é inadequado e ineficaz diz OMS. Disponível em: <http://www. douradosagora.com.br/brasil-mundo/ciencia-saude/priorizar-internacao-compulsoria-para-tratamento-de-drogas-e-inadequado >. Acesso em: 28 jan. 2015.

FOUCAULT, Michel, História da Loucura na Idade Clássica. 9. ed. São Paulo: Perspectiva, 2012.

FRAYZE-PEREIRA, João. 0 que é loucura. Coleção Primeiros Passos, v. 18. São Paulo: Abril Cultural/Brasiliense, 1985.

INSTITUTO fez análises com base nos dados do Censo Demográfico 2010-Migração, nupcialidade, fecundidade também estão no levantamento. G1. Disponível em: http://g1.globo.com/brasil/noticia/2012/04/239-dos-brasileiros-declaram-ter-alguma-deficiencia-diz-ibge.html . Acesso em: 10 jun. 2016.

KENNETT, J. Mental Disorder, Moral Agency and The Self. In: The Oxford Handbook of Bioethics. Bonnie Steinbock(Ed.). New York: Oxford University, p. 90-113, 2007. 
KOTTOW, M. Bioética de Proteção: considerações sobre o contexto latino-americano. In: Schramm, F.M., Rego, S., Braz, M., Palácios, M.(Org.). Bioética: riscos e proteção. Rio de Janeiro: Fiocruz, p. 29-44, 2005.

LIMA, Luana. Saúde mental em situação precária. Jornal Diário do Nordeste. Fortaleza, 27 abril 2013. Disponível em:http://diariodonordeste.verdesmares. com.br/cadernos/cidade/saude-mental-em-situacao-precaria-1.284027. Aceso em: 25 mar. 2017.

LOURENÇO, Luana. Transtornos mentais atingem 23 milhões de pessoas no Brasil. Saúde Ig. Disponível em: http://saude.ig.com.br/transtornos-mentaisatingem-23-milhoes-de-pessoas-no-brasil/n1237686125917.html. Acesso em: 10 jun. 2017.

MADRUGA, Sidney. Pessoas com deficiência e direitos humanos: ótica da diferença e ações afirmativas. Sidney Madruga. São Paulo: Saraiva, p. 103, 2013.

MARMELSTEIN, George. Curso de direitos fundamentais. 4. ed. São Paulo: Atlas, 2013.

MONTEIRO, Fábio de Holanda. A internação psiquiátrica compulsória : uma abordagem à luz dos direitos fundamentais. Biblioteca digital de teses e dissertações- PUCRS. Disponível em: http://tede2.pucrs.br:8080/tede2/handle/ tede/6283. Acesso em: 21 jun. 2017.

PINHEIRO, Gustavo Henrique de Aguiar. Comentários à lei da reforma psiquiátrica: uma leitura constitucional da Lei no 10.216, de 06 de abril de 2001. Fortaleza: Tear da Memória, 2010.

PINTO, Paulo Gabriel Hilu da Rocha. 0 estigma do pecado: a lepra durante a Idade Média. Revista Physis, Rio de Janeiro , v. 5, n. 1, p. 131-144, 1995. Disponível em: http://www.scielo.br/scielo.php?script=sci_arttext\&pid=S010373311995 000100007\&lng=en\&nrm=iso. Acesso em: 08 Abr. 2017.

PIOVESAN, Flávia. Temas de direitos humanos. 4. ed - São Paulo: Saraiva, 2010.

RIOS, Roger Raupp. Direito da antidiscriminação e discriminação por deficiência. In: Deficiência e discriminação. Debora Diniz e Wederson Santos(Org.). Brasília: Letras Livres, p. 78-79, 2010. 
RODRIGUES, José Carlos. 0 Corpo na História. Rio de Janeiro: Fiocruz, p. 112,1999. ROTTERDAM, Erasmo de. Elogio da loucura. Bauru: Edipro, 1995.

SAFFIOTI, Heleieth L. B. Quantos sexos? Quantos gêneros? Unissexo/Unigênero? In: Cadernos de Crítica Feminista. Ano III, n. 2, Recife: SOS- Instituto Feminista para a Democracia, p. 20-21, 2009.

SANCHES, Maria da Glória Perez Delgado. Caso Damião Ximenes Lopes: Resumo. Anotações Direito Internacional. Disponível em: <http://pesquisasdiritointernacional.

blogspot.com.br/2008/02/caso-damio-ximenes-lopes-resumo.html >. Acesso em: 15 fev. 2017.

SARLET, Ingo Wolfgang; MARINONI, Luiz Guilherme; MITIDIERO, Daniel. Curso de Direito Constitucional. 6. ed. São Paulo: Saraiva, p. 256-673, 2017.

SARRETA, Fernanda de Oliveira. "De perto ninguém é normal": Reflexões Sobre a Inclusão social no campo da saúde mental. Serviço Social \& Realidade, Franca, v. 14, n. 1, p.105-118, 2005.

SILVA, Carolina Machado Cyrillo da. A convenção internacional sobre os direitos das pessoas com deficiência e a hierarquia entre os direitos humanos e direitos fundamentais da Constituição Brasileira de 1988. In: Direitos fundamentais e vulnerabilidade social: em homenagem ao professor Ingo Wolfgang Sarlet. Marcia Rodrigues Bertoldi; Alexandre Fagundes Gastal (et al.). Porto alegre: Livraria do advogado, p. 249-250, 2016.

SILVA, Saulo Medeiros da Costa. A condenação do Brasil na Corte Interamericana de Direitos Humanos no caso "Ximenes Lopes" e a postura do Estado brasileiro no processo de garantia de direitos humanos. JUS. Disponível em: <http://jus. com.br/artigos/21056/a-condenacao-do-brasil-na-corte-interamericana-dedireitos-humanos-no-caso-ximenes-lopes-e-a-postura-do-estado-brasileiro-noprocesso-de-garantia-de-direitos-humanos>. Acesso em: 18 fev. 2017.

STEPAN, Nancy Leys. A hora da eugenia: raça, gênero e nação na América Latina. Rio de Janeiro: Fiocruz, 2005 
WARSCHAUER, M.; CARVALHO, Y.M. O conceito de intersetorialidade: contribuições ao debate a partir do programa Lazer e Saúde da prefeitura de Santo André- SP. In: Saúde e Sociedade. São Paulo, v.23, n. 1, p.191-203, 2014.

Recebido em: 9-11-2017

Aprovado em: 31-1-2018

\section{Ingo Wolfgang Sarlet}

Doutor e Pós-Doutor em Direito, Munique, Alemanha; professor titular da Faculdade de Direito e dos Programas de Pós-Graduação em Direito e em Ciências Criminais da PUCRS; professor da Escola Superior da Magistratura (AJURIS). Desembargador no TJRS. Email: iwsarlet@gmail.com.

Pontifíca Universidade Católica do Rio Grande do Sul - PUCRS Av. Ipiranga, 6681, Partenon, Porto Alegre - RS

\section{Gabrielle Bezerra Sales Sarlet}

Pós-doutoranda em Direito pela PUC-RS e pela Universidade de HamburgAlemanha; doutora em Direito pela Universidade de Augsburg, Alemanha; mestre em Direito pela Universidade Federal do Ceará-UFC. Atualmente é professora no PPGD e no curso de graduação em Direito da UNIRITTER- RS. Email: gabriellebezerrasales@gmail.com.

Pontifíca Universidade Católica do Rio Grande do Sul - PUCRS Av. Ipiranga, 6681, Partenon, Porto Alegre - RS 